\title{
Immunofluorescence in Oral Pathology-Part II: Pathology and Immunofluorescent Patterns in Subepidermal Immunobullous Disorders
}

\author{
Roopa S Rao, BR Premalatha, Vijaya Mysorekar
}

\begin{abstract}
The immunobullous disorders are a group of autoimmune diseases in which components of the epidermis and basement membrane zone are targeted, resulting in the formation of cutaneous and mucosal blisters. Based on the level of blistering, the autoimmune blistering diseases may be subdivided into intraepidermal and subepidermal. An exhaustive list of immunobullous disorders is beyond the scope of this review, but those involving oral mucosa are taken into consideration.
\end{abstract}

One major group namely the subepidermal immunobullous diseases which includes bullous pemphigoid (BP), mucosal pemphigoid [cicatricial pemphigoid (CP) or (MMP)], epidermolysis bullosa acquisita (EBA) linear IgA bullous disease (LABD) are discussed in this section. The diagnosis of these diseases requires clinicopathological correlation; immunofluorescence methods provide a useful adjunct to light microscopy. These methods entail the use of fluorescein-linked antibodies to immunoglobulins, complement components, or other proteins either in the skin biopsy or sera. In continuation with part I, the immunofluorescence patterns in the above listed immunobullous disorders are reviewed in detail with a summary of pathogenesis and characteristic histopathological findings.

Keywords: Subepidermal immunobullous diseases, Immunofluorescent patterns, Oral mucosa.
How to cite this article: Rao RS, Premalatha BR, Mysorekar V. Immunofluorescence in Oral Pathology_Part II: Pathology and Immunofluorescent Patterns in Subepidermal Immunobullous Disorders. World J Dent 2012;3(1):68-73.

Source of support: Nil

Conflict of interest: None declared

\section{INTRODUCTION}

The stratified squamous epithelium of the human epidermis forms a continuous barrier against the external environment. The pathophysiology of blistering diseases illustrates how impairments in epithelial adhesion lead to disorders characterized by substantial morbidity and/or mortality. Blistering diseases can be inherited or acquired; most examples of the latter are autoimmune in nature and are characterized by autoantibodies that target adhesion junctions promoting either cell-cell or or cell-matrix adhesion in skin. ${ }^{1}$ Patients with bullous pemphigoid (BP) and other autoimmune subepidermal blistering diseases have autoantibodies that target autoantigens in epidermal basement membrane (BM) $)^{2,3}$ (Fig. 1 and Table 1).

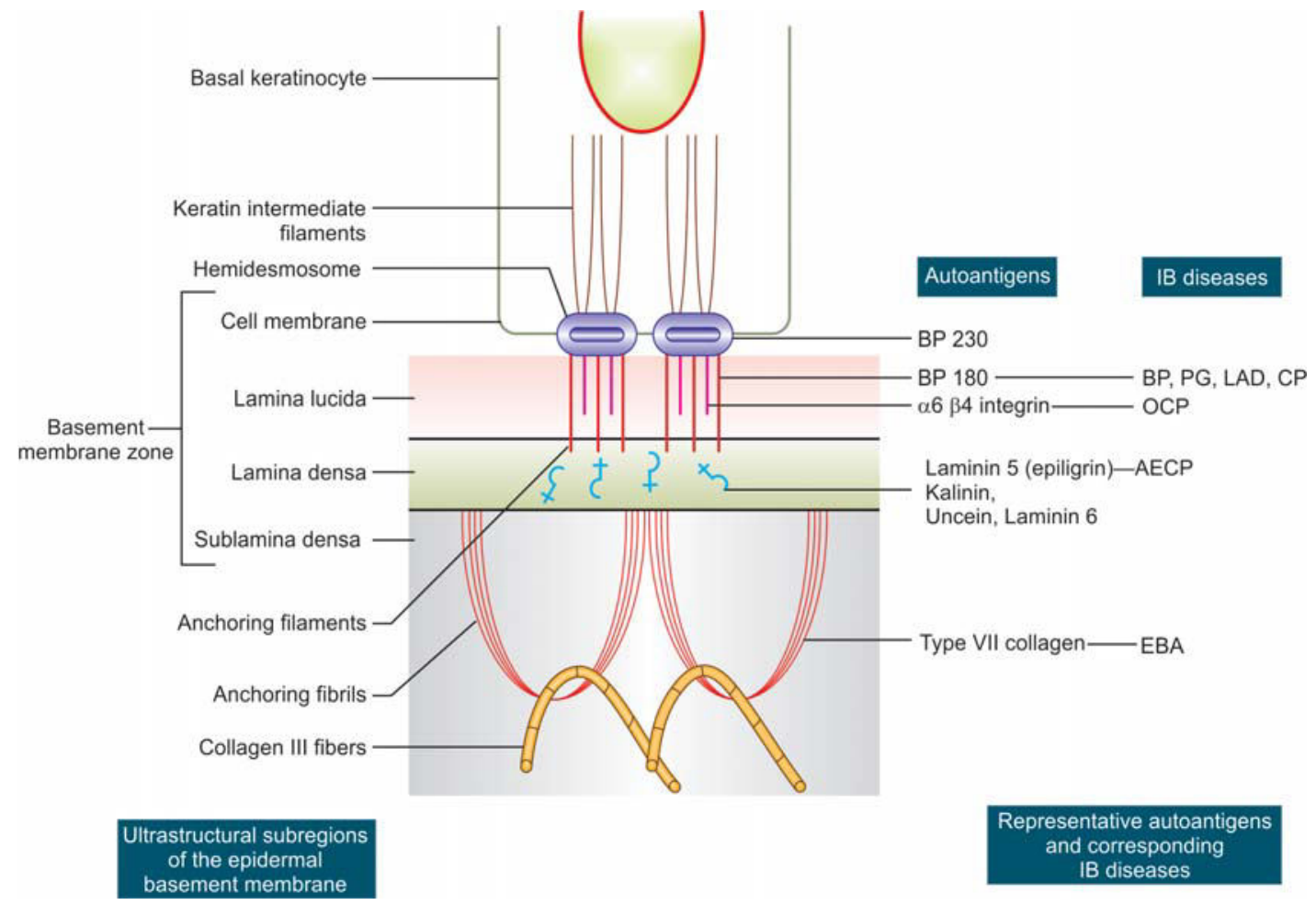

Fig. 1: Ultrastructural subregions of the epidermal basement membrane and representative autoantigens of corresponding immunobullous diseases. AECP: Antiepiligrin cicatricial pemphigoid; CP: Cicatricial pemphigoid; EB: Epidermolysis bullosa; IB: Immunobullous; LAD: Linear IgA dermatosis; OCP: Ocular cicatricial pemphigoid 
Table 1: Immunofluorescence findings in immunobullous disorder ${ }^{46,47}$

\begin{tabular}{|c|c|c|c|c|c|c|c|c|}
\hline \multirow{2}{*}{$\begin{array}{l}\text { Subepidermal } \\
\text { bullous disorders }\end{array}$} & \multicolumn{5}{|c|}{ Antibodies } & \multirow{2}{*}{$\begin{array}{l}\text { Target } \\
\text { antigen }\end{array}$} & \multirow[t]{2}{*}{ Structural target } & \multirow{2}{*}{$\begin{array}{c}\text { Immunofluorescence } \\
\text { patterns }\end{array}$} \\
\hline & $\lg G$ & $\lg M$ & $\lg A$ & C3 & Fibrin & & & \\
\hline Bullous pemphigoid & $+v e$ & -ve & -ve & $+v e$ & -ve & $\begin{array}{l}\text { BP230 } \\
\text { BP180 }\end{array}$ & $\begin{array}{l}\text { Hemidesmosome } \\
\text { anchoring filament } \\
\text { complexes }\end{array}$ & $\begin{array}{l}\text { Homogenous linear } \\
\text { band at the BMZ }\end{array}$ \\
\hline Cicatricial pemphigoid & $+v e$ & -ve & -ve & $+v e$ & -ve & $\begin{array}{l}\text { BP180, } \\
\text { laminin, } \\
\text { alpha } 4 \text { and } \\
\text { beta } 6 \\
\text { subunits of } \\
\text { integrin }\end{array}$ & $\begin{array}{l}\text { Basement or } \\
\text { hemidesmosome }\end{array}$ & $\begin{array}{l}\text { Linear deposition of } \\
\text { IgG and C3 along the } \\
\text { BMZ }\end{array}$ \\
\hline $\begin{array}{l}\text { Epidermolysis bullosa } \\
\text { acquisita }\end{array}$ & $+\mathrm{ve}$ & $+v e$ & $+v e$ & $+v e$ & -ve & Collagen 7 & & $\begin{array}{l}\text { Linear IgG and/or } \\
\text { C3 at BMZ }\end{array}$ \\
\hline $\begin{array}{l}\text { Linear IgA bullous } \\
\text { dermatosis }\end{array}$ & $-v e$ & $-v e$ & $+v e$ & $-v e$ & -ve & $\begin{array}{l}\text { LAD } 285 \\
\text { BP180 }\end{array}$ & $\begin{array}{l}\text { Hemidesmosome- } \\
\text { anchoring } \\
\text { filament } \\
\text { complexes }\end{array}$ & $\begin{array}{l}\text { Linear deposition of } \\
\lg A \text { at } B M Z\end{array}$ \\
\hline
\end{tabular}

Circulating autoantibodies can be demonstrated in the patient's skin biopsies by direct immunofluorescence techniques (DIF) and in the patient's serum by indirect immunofluorescence technique (IIF), the techniques and methodologies have been reviewed exhaustively in the part I of this series. The relative simplicity, accuracy and the combination of the specificity of immunology with the localization of histopathology has made immunofluorescence an indispensible technique in the diagnosis of immunobullous diseases.

In this part, the main theme is focused on pathology and immunofluorescent patterns in subepidermal immunobullous disorders of pemphigoid group involving oral cavity.

The pemphigoid group of diseases has been classified into two main clinical subgroups: Bullous pemphigoid, which involves skin but $30 \%$ of the time involves oral mucous membranes as well; and cicatricial pemphigoid (mucous membrane pemphigoid), which involves mucous membranes (usually oral or conjuctival) and skin to lesser extent (20\%). Today, this group of diseases is categorized into two main clinical groups: Cutaneous and mucosal pemphigoid. The mucosal pemphigoids are subclassified into three subgroups as follows: Cicatricial pemphigoid, oral mucous membrane pemphigoid and ocular pemphigoid. ${ }^{4}$

\section{BULLOUS PEMPHIGOID (CUTANEOUS PEMPHIGOID)}

Bullous pemphigoid (BP) is the most common of all autoimmune blistering conditions. It is primarily a skin disease, forming oral lesions in only 8 to $39 \%$ of cases. ${ }^{4,5}$

\section{Pathogenesis}

Blister formation is found to occur within the lamina lucida of the basement membrane, causing a loss of anchoring filaments and hemidesmosomes. There are IgG autoantibodies specific for the hemidesmosomal BP antigen BP230 (BPAg1) and BP180 (BPAg2). ${ }^{6,7}$ The binding of the antibodies at the basement membrane activates complement and inflammatory mediators. Although BPAg2 has been identified as the major antigen involved with BP disease development, autoantibodies against $\alpha 6$ integrin and laminin- 5 were identified in patients affected by BP. IL-5, an interleukin with eosinophil chemoattractant and activation properties has been found in the skin of patients with BP. ${ }^{4,5,8}$

\section{Histopathology}

The perilesional margin of a bulla shows separation of the epithelium from the connective tissue at the basement zone, resulting in subepithelial separation. ${ }^{9}$ The BM remains attached to the connective tissue rather than to the overlying separated epithelium. Modest numbers of both acute and chronic inflammatory cells are typically seen in the lesional area, and the presence of eosinophils within the bulla itself is characteristic ${ }^{5,10}$ (Fig. 2).

\section{Immunofluorescent Patterns and Its Significance}

$D I F$ : Testing of perilesional and uninvolved skin shows a thick linear band of $\mathrm{C} 3$ deposition along the basement membrane zone (BMZ) at the dermoepidermal junction in virtually $100 \%$ of cases (Fig. 3) and $\operatorname{IgG}$ in 65 to $95 \%$, $11-14$ (Fig. 4).

Salt-splitting direct techniques enhance the sensitivity of immunoreactant detection and help to differentiate between the various immunobullous disorders with immunoreactants deposited at the basement membrane zone. ${ }^{15} \mathrm{IgG}$ will localize to the roof of the split in the 


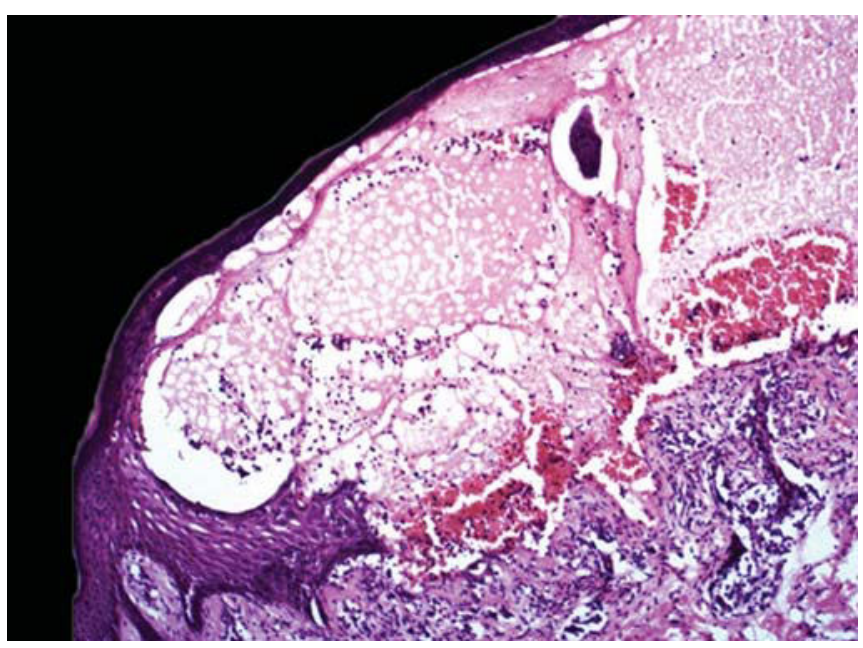

Fig. 2: Bullous pemphigoid: H\&E stained section at $10 \times$ showing a subepidermal blister containing proteinaceous fluid and inflammatory cells. The papillary dermis shows mononuclear inflammatory cell infiltration

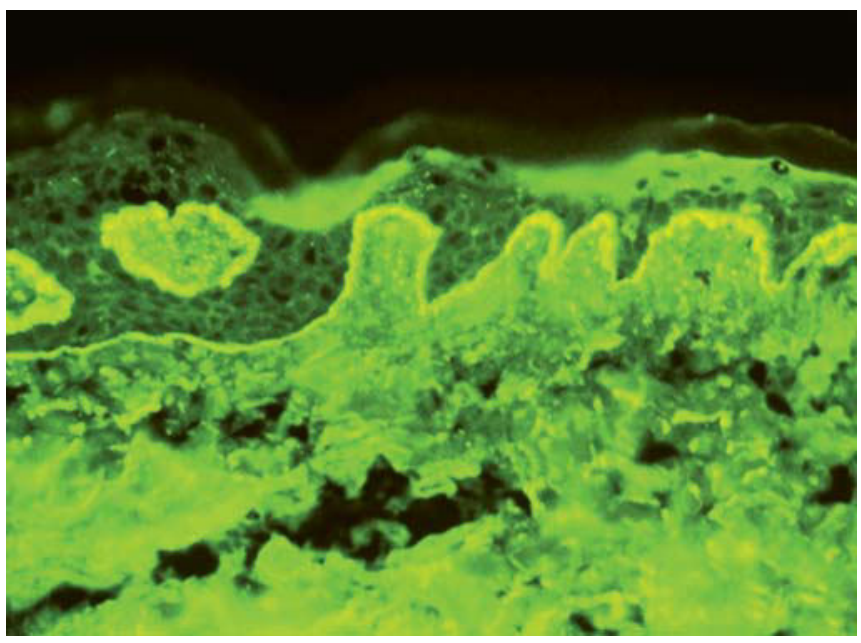

Fig. 3: Bullous pemphigoid: DI showing linear deposition of C3 at the dermoepidermal junction

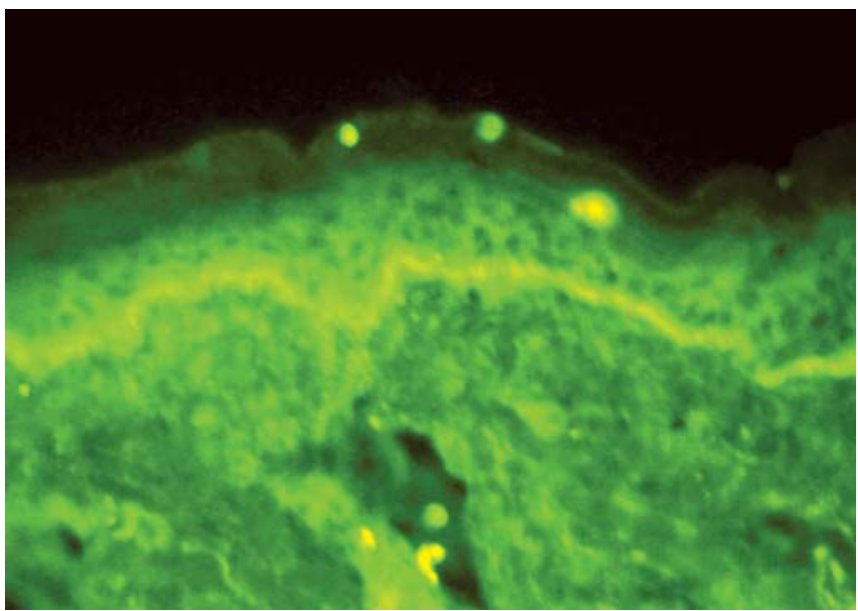

Fig. 4: Bullous pemphigoid: DI showing linear deposition of IgG at the dermoepidermal junction

majority of patients, to both roof and floor in $10 \%$ but occasionally to the floor alone. ${ }^{16,17} \mathrm{C} 3$ will always bind to both roof and floor. ${ }^{18}$
Circulating IgG antibodies may be found in $95 \%$ of cases by using salt-split skin as a substrate. ${ }^{19}$ The antibodies are predominantly IgG1 and IgG4 subclasses. ${ }^{20}$ The use of saltsplit skin substrate will usually reveal BP antisera binding to the epidermal side alone or to both epidermal and dermal aspects but occasionally antisera will bind only to the dermal aspect. In such cases, toad skin substrate may be utilized to confirm the diagnosis as it contains the bullous pemphigoid antigens. ${ }^{21}$ Thus, selection of substrate plays an important role in the detection of circulating antibodies. ${ }^{22}$

IIF: Studies reveal circulating antibasement membrane zone IgG antibodies in 70 to $80 \%$ of cases. Similarly deposition of $\operatorname{IgG}$ and $\operatorname{IgM}$ are observed in about $25 \%$ of cases. Correlation exists between the antibody titer and the clinical severity of the disease. ${ }^{23}$ The IgG is located within the lamina lucida. ${ }^{1,4}$

\section{MUCOSAL PEMPHIGOIDS \\ Cicatricial Pemphigoid or Mucous Membrane Pemphigoid (MMP)}

Pemphigoid came to include cicatricial pemphigoid now renamed as mucous membrane pemphigoid MMP lesions in the oral cavity are present in $85 \%$ of patients. The oral mucosa is often the initial site of MMP lesions. Desquamative gingivitis is the main oral feature of MMP. ${ }^{24}$

\section{Variants of MMP with Oral Lesions}

At least six variants or subsets of MMP with different antigenic specificity of autoantibodies and patterns of immunopathology are now recognized, but new immunemediated, subepithelial, blistering diseases with oral lesions that simulate have also been described. ${ }^{24}$

The main oral variants are as follows

1. Oral pemphigoid or OMMP (Oral lesions only): The target antigen for oral pemphigoid is still unclear; though antibodies against a $168-\mathrm{kDa}$ oral mucosal protein have been seen in a few patients. ${ }^{25}$ It has a low incidence of findings on indirect immunofluorescence. ${ }^{26}$

2. Pemphigoid with more widespread clinical features (oral and extraoral lesions): Antiepiligrin pemphigoid (AECP): Blisters in mucous membrane and skin are rare and characterized by serologic reactivity only to the dermal side of salt-split skin. The targeted antigens are subunits of laminin 5 (epiligrin). ${ }^{27}$

\section{Pathogenesis}

The pathogenesis of MMP probably includes an autoantibody-induced complement-mediated sequestration of leukocytes (mainly neutrophils) with a resultant release 
of cytokines and leukocyte enzymes, and the detachment of the basal cells from the basement membrane zone, and possibly some complement-mediated lysis of cells. ${ }^{24}$

The known autoantigens include (a) epiligrin or laminin 5, (b) BPAg2 and BPAg1. All of these antigens occur within the lamina lucida, with epiligrin present in the lower lamina lucida. The autoantibodies involved in MMP are directed against these antigens, either in the basement membrane or hemidesmosomes. ${ }^{7,28}$

\section{Histopathology}

Histologically, MMP is characterized by junctional separation at the level of the basement membrane that gives rise to a sub-basilar split with a chronic inflammatory infiltrate in the lamina propria that contains eosinophils, lymphocytes and neutrophils. 4,24

\section{Immunofluorescent Patterns and Its Significance}

$D I F$ : Perilesional skin and mucosae have linear deposition of $\mathrm{IgG}$ and $\mathrm{C} 3$ along the $\mathrm{BMZ}$ in $80 \%$ of cases in a homogeneous manner. IgA and IgM are deposited less often. Deposition of immunoreactants along the BMZ of mucosal mucous glands appears to be a specific finding in cicatricial pemphigoid. ${ }^{24,29,30}$

IIF : Positive circulating antibodies are detected by IF and immunoblot assays in 5\% patients. IIF testing of serum yields variable results depending on the substrate used (monkey esophagus, guinea pig esophagus, normal human skin, salt-split skin). Circulating antibodies may be readily demonstrated when salt-split human skin is used as substrate, in which IgG may be localized only to the roof. ${ }^{31}$

Indirect immunofluorescence using salt-split mucosa provides a more sensitive assay, can show antibasement membrane zone antibodies, and distinguishes between antigens on the epithelial side of the split (4 integrin and BPAg2) and those on the lamina propria side (laminin 5). Immunoblot assays are more specific than IF. ${ }^{24}$

Circulating $\operatorname{IgG}$ and $\operatorname{IgA}$ antibodies are usually of low titer and are detected in 20 to $30 \%$ with standard IIF methods but this may be increased to $80 \%$ by the use of salt-split skin substrate. IgM antibodies may also be found. The binding of antibodies is most commonly to the epidermal aspect of salt-split skin but may be to both sides or to the dermal side alone. ${ }^{19}$ IgG antibodies are usually IgG and IgG4 while IgA antibodies are always of IgAl subclass. Titers do not relate to disease extent nor activity. ${ }^{29,32}$

\section{EPIDERMOLYSIS BULLOSA ACQUISITA (EBA)}

It is an IgG-mediated autoantibody disease with oral lesions present in nearly $50 \%$ of the cases reported along with cutaneous lesions. 5

\section{Pathogenesis}

It is an immunologically-mediated condition characterized by autoantibodies directed against type VII collagen, the principle component of the anchoring fibrils. As a result, their immunologic destruction results in the formation of bullous lesions of the skin and mucosa with minimal trauma. ${ }^{5}$

\section{Histopathology}

A cell-poor subepidermal split with variable dermal cellular infiltration is seen on biopsy. ${ }^{33}$

\section{Immunofluorescent Patterns and Its Significance}

$D I F$ : $\mathrm{IgG}$ is deposited linearly along the $\mathrm{BMZ}$ of perilesional skin in all active cases. $\operatorname{IgA}, \operatorname{IgM}$ and $\mathrm{C} 3$ are also often present. Salt-splitting DIF techniques reveal a dermal pattern of immunoreactant deposition in all cases. ${ }^{34,35}$

IIF: The detection and titer of circulating IgG anti-BMZ antibodies may be increased from 25 to $50 \%$ using standard IIF methods 34,35 to and 50 to $85 \%$ with salt-split skin substrate. ${ }^{36,37}$ The antibodies in EBA have specificity for the globular carboxyl terminus of type VII collagen and are deposited beneath the lamina densa. ${ }^{38,39}$ Therefore, on saltsplit skin studies, $\operatorname{IgG}$ is on the floor and not on the roof of the split. ${ }^{40}$

\section{Linear IgA Disease}

Linear IgA disease is a rare autoimmune disease involving skin and oral mucosa. It is not considered a part of the pemphigoid group but is a similar disease in which autoantibodies attack basement membrane proteins. ${ }^{4}$

\section{Histopathology}

The distinguishing feature of linear $\operatorname{IgA}$ disease is the presence of $\operatorname{IgA}$ in a homogeneous, linear pattern at the basement membrane zone in lesional and perilesional tissue. The vesicles are subepithelial and occur within the lamina lucida or below the basal lamina. ${ }^{4}$

The histology is in many cases identical to that found in dermatitis herpetiformis but may also resemble bullous pemphigoid. $^{33}$

\section{Immunofluorescent Patterns and Its Significance}

DIF: Reveals linear IgA along the basement membrane zone in the perilesional skin in $100 \%$ of cases. It has been suggested that if $\operatorname{IgA}$ deposits are more intense than the 
IgG deposits, and C3 deposition is strong, then linear IgA dermatosis is the best diagnosis. ${ }^{14,41,42}$

Epidermal, dermal and combined patterns of $\operatorname{Ig} \mathrm{A}$ deposition may be seen with salt-splitting of the biopsy. ${ }^{43}$ Children more commonly have positive indirect immunofluorescence than adults with figures of $72 \%$ and $20 \%$ respectively obtained in one study using standard techniques. ${ }^{44}$ Salt-split skin substrate will increase the detection rate and titer of antibodies with binding to either the roof or floor, the former being more common. ${ }^{45,46}$

\section{CONCLUSION}

Immunofluorescence combines the specificity of serology and localization of histology. Thus, it helps in visualization of antigen-antibody reaction in situ. It is an invaluable tool in the diagnosis of immunobullous lesions.

\section{ACKNOWLEDGMENTS}

I personally thank Dr S Kumar, Dean and Principal of MS Ramaiah Medical College and Hospital for having permitted us to use the facilities available at MSRMC and associate with the medical faculty in preparation of this manuscript.

\section{REFERENCES}

1. Udey MC, Stanley JR. Pemphigus - diseases of antidesmosomal autoimmunity. JAMA 1999;282:572-76.

2. Yancey KB, Egan CA. Pemphigoid: Clinical, histologic, immunopathologic, and therapeutic considerations. JAMA 2000;284:350-56.

3. Schmidt E, Zillikens D. Autoimmune and inherited subepidermal blistering diseases: Advances in the clinic and the laboratory. Adv Dermatol 2000;16:113-57.

4. Marx Robert E, Diane Stern. Oral and Maxillofacial Pathology (1st ed). Quintessence 2003.

5. Neville Damm Allen Bonquot. Oral and maxillofacial pathology. (2nd ed). WB Saunders Company 2002.

6. Meuller S, Klaus-Kovtun V, Stanley JR. A230kD basic protein is the major bullous pemphigoid antigen. J Invest Dermatol 1989;92:33.

7. Labib RS, Anhalt GJ, Patel HP, et al. Molecular heterogeneity of the bullous pemphigoid antigens as detected by immunoblotting. J Immunonol 1986;136;1231.

8. Van den Bergh F, Giudice GJ. BP180 (type XVII collagen) and its role in cutaneous biology and disease. Adv Dermatol 2003; 19:37-71.

9. Bushkell LL, Jordan RE. Bullous pemphigoid: A cause of peripheral blood eosinophilia. J Am Acad Dermatol 1983;8:648.

10. Rajendran R, Sivapathasundaram B. Shafer's Textbook of Oral Pathology (5th ed), Elsevier 2006.

11. Harrist TJ, Mihm MC. Cutaneous immunopathology: The diagnostic use of direct and indirect immunofluorescence techniques in dermatologic disease. Hum Pathol 1979;10:625.

12. Ahmed AR, Maize JC, Provost TT. Bullous pemphigoid: Clinical and immunologic follow-up after successful therapy. Arch Dermatol 1977;113:1043-46.
13. Provost TT, Tomasi TB. Immunopathology of bullous pemphigoid: Basement membrane deposition of IgE, alternate pathway components and fibrin. Clin Exp Immunol 1974; 18:193-200.

14. Cellular pathology technique. CF A Cullings (4th ed), Butterworths 1984.

15. Domloge-Hultsch N, Bisalbutra P, Gammon WR, Yancey KB. Direct immunofluorescence microscopy of $1 \mathrm{~mol} / 1$ sodium chloride-treated patient skin. J Am Acad Dermatol 1991;24: 946-51.

16. Wuepper KD. Repeat direct immunofluorescence to discriminate pemphigoid from epidermolysis bullosa acquisita. Arch Dermatol 1990;126:1365.

17. Gammon WR, Kowalewski C, Chorzelski TP, et al. Direct immunofluorescence studies of sodium chloride-separated skin in differential diagnosis of bullous pemphigoid and epidermolysis bullosa acquisita. J Am Acad Dermatol 1990; 22:664.

18. Mehregan DR, Oursler JR, Leiferman KM, et al. Paraneoplastic pemphigus: A subset of patients with pemphigus and neoplasis. J Cut Pathol 1993;20:203-10.

19. Kelly SE, Wojnarowska F. The use of chemically split tissue in the detection of circulating anti-basement membrane zone antibodies in bullous pemphigoid and cicatricial pemphigoid. Br J Dermatol 1988;118:31-40.

20. Kelly SE, Cerio R, Bhogal BS, Black MM. The distribution of IgG subclasses in pemphigoid gestationis: $\mathrm{PG}$ factor is an IgG 1 autoantibody. J Invest Dermatol 1989;92:695-98.

21. Pang BK, Lee YS, Ratnam KV. Floor-pattern salt-split cannot distinguish bullous pemphigoid from epidermolysis bullosa: Use of toad skin. Arch Dermatol 1993;129:744-46.

22. Anuradha, et al. Current concepts of immunofluorescence in oral mucocutaneous diseases. Journal of Oral and Maxillofacial Pathology: Sep-Dec 2011;15(3).

23. Sams WM, Jordon RD. Correlation of pemphigoid and pemphigus antibody with activity of disease. Br J Dermatol 1971;84:7.

24. Scully C, Lo Muzio L. Oral mucosal diseases: Mucous membrane pemphigoid. British Journal of Oral and Maxillofacial Surgery 2008;46:358-66.

25. Ghohestani RF, Nicolas JF, Rousselle P, Claudy AL. Identification of a $168-\mathrm{kDa}$ mucosal antigen in a subset of patients with cicatricial pemphigoid. J Invest Dermatol 1996;107:136-39.

26. Mobini N, Nagarwalla N, Ahmed AR. Oral pemphigoid. Subset of cicatricial pemphigoid? Oral Surg Oral Med Oral Pathol Oral Radiol Endod 1998;85:37-43.

27. Egan CA, Lazarova Z, Darling TN, Yee C, Yancey KB. Antiepiligrin cicatricial pemphigoid: Clinical findings, immunopathogenesis, and significant associations. Medicine (Baltimore) 2003;82:177-86.

28. Domloge-Hultsch N, Anhalt GJ, Gammon WR, et al. Antiepiligrin cicatricial pemphigoid: A subepithelial bullous disorder. Arch Dermatol 1994;130:1521.

29. Ahmed AR, Kurgis BS, Rogers RS. Cicatricial pemphigoid. J Am Acad Dermatol 1991;24:987-1001.

30. Fine JD, Neises GR, Katz SI. Immunofluorescence and immunoelectron microscopic studies in cicatricial pemphigoid. J Invest Dermatol 1984;82:39-43.

31. Venning V, Nayar M, Wojnarowska F, et al. Cicatricial pemphigoid: Analysis of circulating and bound antibody isotypes and C3. Br J Dermatol 1992;127:440. 
32. Weedon D. The vesiculobullous reaction pattern. In: Weedon D (Ed): Systemic Pathology: The Skin (3rd ed). Edinburgh, Churchill-Livingstone 1992;9:127-80.

33. Briggaman RA, Gammon WR, Woodley DT. Epidermolysis bullosa acquisita of the immunopathological type (dermolytic pemphigoid). J Invest Dermatol 1985;85:79-84s.

34. Wilson BD, Birnkrant AF, Beutner EH, Maize JC. Epidermolysis bullosa acquisita: A clinical disorder of varied etiologies. J Am Acad Dermatol 1980;3:280-91.

35. Gammon WR, Fine JD, Briggaman RA. Immunofluorescence on split skin for the detection and differentiation of basement membrance antibodies. J Am Acad Dermatol 1992;27:79-87.

36. Gammon WR, Woodley DT, Dole KC, Briggaman RA. Evidence that antibasement membrane antibodies in bullous eruption of systemic lupus erythematosus recognize epidermolysis bullosa acquisita autoantigen. J Invest Dermatol 1985; 84:472-76.

37. Nieboer C, Boorsma DM, Woerdeman MJ, et al. Epidermolysis bullosa acquisita: Immunoflourescence, electron microscope and immunoelectron microscopic studies in four patients. Br J Dermatol 1980;102:383.

38. Woodley DT, Burgeson RE, Lunstrum G, et al. The epidermolysis bullosa acquisita antigen is the globular carboxy terminus of type VII procollagen. J Clin Invest 1988;81:683.

39. Gammon WR, Fine JD, Briggaman RA. Autoimmunity to type VII collgen: Features and roles in basement membrane zone injury. In: Fine JD (Ed). Bullous diseases. New York: Igaku Shoin 1993;75.

40. Adachi A, Tani M, Matsubayashi S, et al. Immunoelectron microscopic differentiation of linear IgA bullous dermatosis of adults with coexistence of IgA and IgG deposition from bullous pemphigoid. J Am Acad Dermatol 1992;27:394.

41. Peterson MJ, Gammon WR, Briggaman RA. A case of linear IgA disease presenting as initially with IgG immune deposits. J Am Acad Dermatol 1986;14;1014.

42. Bhogal BS, Stefanato CM, Chorzelski TP, et al. A study to determine the site of $\operatorname{IgA}$ antibody deposition in linear IgA bullous dermatoses using direct immunofluorescence of sodium chloride-separated skin. J Invest Dermatol 1992;98:525.

43. Wojnarowska F, Marsden RA, Bhogal B, Black MM. Chronic bullous disease of childhood, childhood cicatricial pemphigoid, and linear IgA disease of adults. J Am Acad Dermatorl 1988; 19:792-805.

44. Willsteed E, Bhogal BS, Black MM, et al. Use of $1 \mathrm{M} \mathrm{NaCI}$ split skin in the indirect immunofluorescence of the linear IgA bullous dermatoses. J Cutan Pathol 1990;17:144-48.

45. Dmochowski M, Hashimoto $\mathrm{T}$, Bhogal BS, et al. Immunoblotting studies of linear IgA disease. J Dermatol Sci 1993;6:194-200.

46. Chan PT. Clinical features and diagnosis of common autoimmune bullous diseases in Hong Kong Medical bulletin October 2008;13(10).

47. Mohan KH, Pai Sathish, Rao Raghavendra, Sripathi H, Prabhu Smitha. Techniques of immunofluorescence and their significance. Indian Journal of Dermatology, Venereology and Leprology 2008;74(4):415-19.

\section{ABOUT THE AUTHORS}

\section{Roopa S Rao (Corresponding Author)}

Professor, Department of Oral Pathology, MS Ramaiah Dental College and Hospital,Bengaluru,Karnataka,India,e-mail:drroopasrao1971@gmail.com

\section{BR Premalatha}

Senior Lecturer, Department of Oral Pathology, MS Ramaiah Dental College and Hospital, Bengaluru, Karnataka, India

\section{Vijaya Mysorekar}

Professor, Department of Pathology, MS Ramaiah Medical College and Hospital, Bengaluru, Karnataka, India 